ARTICLE

УАК 595.443

\title{
REVIEW OF FAUNAL INVESTIGATION OF PREDATORY FLIES OF THE FAMILY DOLICHOPODIDAE (DIPTERA) IN IRAN
}

\author{
Igor Ya. Grichanov \\ All-Russian Institute of Plant Protection, Podbelskogo 3, St.Petersburg, Pushkin, 196608 Russia \\ E-mail:grichanov@mail.ru
}

The data on Dolichopodidae from Iran since 1913 are reviewed. Liancalus virens (Scopoli, 1763) is recorded for the first time for Iran. A list of Dolichopodidae of the country includes 114 species.

Key words: Diptera, Dolichopodidae, Palearctic Region, Iran, new record, fauna.

\section{ОБЗОР ФАУНИСТИЧЕСКИХ ИСАЕАОВАНИЙ ХИЩНЫХ МУХ CЕМЕЙСТВА DOLICHOPODIDAЕ (DIPTЕRA) ИРАНА}

Гричанов И.Я.

Всероссийский институт защиты растений, шоссе Подбельского 3, Санкт-Петербург-Пуикин 196608, Россия.

\begin{abstract}
Приведен обзор данных по фауне мух-зеленушек Ирана, опубликованных с 1913 года. Liancalus virens (Scopoli, 1763) указан впервые Аля страны. Число известных из Ирана видов семейства достигло 114.

Kлючевые слова: Diptera, Dolichopodidae, Палеарктика, Иран, новое указание, фауна.
\end{abstract}

Следует цитировать / Citation:

Гричанов И.Я. (2016). Обзор фаунистических иследований хищных мух семейства Dolichopodidae (Diptera) Ирана.

Acta Biologica Sibirica, 2 (4), 11-14.

Grichanov, I.Ya. (2016). Review of faunal investigation of predatory flies of the family Dolichopodidae (Diptera) in Iran.

Acta Biologica Sibirica, 2 (4), 11-14.

Поступимо в реАакцию / Submitted: 31.08 .2016

Принято к публикации / Accepted: 10.10 .2016

cross ref $_{\text {http://dx.doi.org/10.14258/abs.v2i4.1627 }}$

С Гричанов, 2016

Users are permitted to copy, use, distribute, transmit, and display the work publicly and to make and distribute derivative works, in any digital medium for any responsible purpose, subject to proper attribution of authorship.

$(\mathrm{cc}) \mathrm{BY}$

This work is licensed under a Creative Commons Attribution 3.0 License

\section{INTRODUCTION}

The long-legged flies belong to one of the largest families (Dolichopodidae) in extant Diptera. Approximately 7600 described species and 250 genera are known in the world fauna (Grichanov, 2014). Adults and larvae of dolichopodids are mainly predacious, except for one genus (Thrypticus), the larvae of which are known to be phytophagous and living inside stems of cereal grasses. Some genera (Medetera, Neurigona) are known to be associated with tree trunks where their larvae are predaceous mainly on bark beetles (Coleoptera). Medetera flies can also feed on aphids, thrips and mites populating plants of grain, vegetable, fruit and other cultures, together with other entomophages regulating development and reproduction of dangerous pests, especially at irrigation farming (Grichanov, 2007).

\section{REVIEW OF FAUNAL INVESTIGATION}

The first contribution to the fauna of Dolichopodidae of Iran was made by Th. Becker and P. Stein (1913) who treated material collected by N. Zarudny (St. Petersburg, Russia) in Khorasan, Kerman and Sistan and Baluchestan provinces during 1898 and 1901 expeditions (Figure 1). The authors identified 8 mainly halophilic species of long-legged flies: Dolichopus notatus Staeger, 1842 (as Dolichopus notabilis Zetterstedt, 1843); Tachytrechus planitarsis Becker, 1907; Hydrophorus praecox (Lehmann, 1822); Thinophilus argyropalpis Becker, 1907; T. indigenus Becker, 1902; T. quadrimaculatus Becker, 1902; T. spinitarsis Becker, 1907; Syntormon pallipes (Fabricius, 1794).

A.A. Stackelberg (1941) mentioned Poecilobothrus regalis (Meigen, 1824) from northwestern Iran in the collection of the Zoological Institute (St.Petersburg). Negrobov, Stackelberg (1974) described a new species Medetera pavlovskii Negrobov, 1972 with the type locality "Shachrud" (probably, Shahrood, a river in northern Iran), from the collection of the same Institute, found by the Russian zoologist Yevgeny Pavlovsky (St. Petersburg) in 1942.

O.P. Negrobov \& L. Matile (1974) described two new for science Syntormon species collected by A. Giordani Soika (Venice, Italy) in Khorramshahr and Qasr-e Shirin in 1956, i.e. Syntormon giordanii Negrobov, 1974 and S. iranicus Negrobov, 1974. The authors added also 10 species new for the country (4 species by females only) that were collected by L. Matile (Paris, France) in 1965 in Guilan mainly, in Mazandaran, Azerbaijan and Gorgan provinces: Argyra argentina (Meigen, 1824); A. diaphana (Fabricius, 1775); Chrysotus gramineus (Fallen, 
1823); Gymnopternus metallicus (Stannius, 1831) (as Hercostomus metallicus); Hercostomus chetifer (Walker, 1849); H. longiventris (Loew, 1857); Neurigona erichsoni (Zetterstedt, 1843); Rhaphium appendiculatum Zetterstedt, 1849 (as R. macrocerum); Sybistroma discipes (Germar, 1821); S. leptocerca (Stackelberg, 1949) (as Hercostomus leptocercus). In addition, Negrobov (1991) included Iran in the area of medeterine species Thrypticus intercedens Negrobov, 1967 without indicating original material, and Maslova (2006) mentioned Chrysotus angulicornis Kowarz, 1874 for Iran, not giving original material.

\section{Persische Dipteren von den Expeditionen des Herrn N. Zarudny 1898 und 1901.}

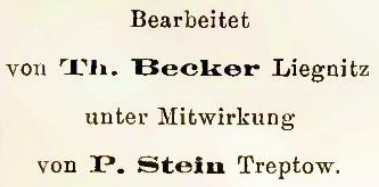

\section{EINLEITUNG.}

Die nachstehende Arbeit umfasst die Bestimmung und Bearbeitung einer Reihe von Dipteren, welche während zweier Expeditionen nach Persien in den Jahren 1898 und 1901 von dem Herrn N. Z Z ARUDNY erbeutet wurden. Diese Sammlung war ursprünglich Eigentum des Herrn Тв. Pleske, ist aber von letzteren dem Zoologischen Museum der Kais. Akademie der Wissenschaften zu St. Petersburg geschenkweise überlassen.

Herr N. Zarudyr, um seine Reise zu skizzieren, hat in nachstehenden Zeitabschnitten folgende Provinzen und Landschaften berïhrt:

Im Jahre 1898: vom 8. April bis 1. Mai die Provinz Chorassan mit den Landschaften Bechars und Sirkuch; vom 7. Mai bis 20. September die Provinz P.-Beludshistan mit den Landschaften Kirman und Sseistan; vom 28. September bis 11. Oktober die Provinz Chorassan.

Im Jahre 1901: vom 9. Februar bis 21. Mai die Provinz P.-Beludshistan; vom 10. Juni bis 10. August Chorassan.

Fig. 1. First page of the work by Becker, Stein (1913).

As a result, 24 species were reported from Iran before the recent regular collecting of dolichopodids by Iranian students and researchers. The author of this paper identified also an Iranian collection of pinned dolichopodids in the Zoological Museum of Moscow State University, Moscow, Russia (Grichanov et al. 2010). The flies were collected by the Russian diplomat N.N. Filippov (under the pseudonym Zhenzhurist) in 19371938 at Rasht, "Jarjarud", "Shimran", "Pahlevi" [=Bandar-e Anzali] and Tehran (northern Iran). Argyra leucocephala (Meigen, 1824), Dolichopus excisus Loew, 1859, D. griseipennis Stannius, 1831, D. latilimbatus Macquart, 1827, D. nubilus Meigen, 1824, D. perversus Loew, 1871, D. signifer Haliday, 1832, Tachytrechus notatus (Stannius, 1831), Sympycnus simplicipes Becker, 1908 and Syntormon zelleri (Loew, 1850) from that collection were reported from Iran for the first time (Grichanov et al. 2010). Later Sciapus iranicus Grichanov, Negrobov was described from the same collection as new for science (Grichanov, Negrobov, 2014). In addition, Liancalus virens (Scopoli, 1763) was overlooked in Zhenzhurist's collection, being here recorded from Iran for the first time $(5 \hat{\jmath}, 19$, Iran: [Tehran,] Shimran, 5.XII.1936).

Mahmoud Alikhani (the Islamic Azad University, Arak Branch, Iran) collected dolichopodid flies during 2008-2009 from about 50 sampling sites on crop and non-crop plants in Markazi province, Arak region and suburb (Grichanov et al. 2010). The presence of Chrysotus angulicornis in Iran was confirmed. Chrysotus suavis Loew, 1857, Dolichopus clavipes Haliday, 1832 and Rhaphium micans (Meigen, 1824) were firstly found in the country.

Dr. Samad Khaghaninia and Yaser Gharajedaghi (the University of Tabriz, Tabriz, Iran) conducted a survey during 2009-2013 in order to study the family Dolichopodidae in East Azerbaijan province. The following species were recorded from Iran for the first time: Dolichopus longitarsis Stannius, 1831, D. salictorum Loew, 1871, D. simplex Meigen, 1824, Hercostomus fulvicaudis (Haliday, 1851), Sciapus flavicinctus (Loew, 1857) and Sybistroma nodicornis Meigen, 1824 (Khaghaninia et al., 2013a); Hercostomus gracilis (Stannius, 1831), H. libanicola Parent, 1933, H. rusticus (Meigen, 1824), Poecilobothrus armeniorum (Stackelberg, 1933), P. basilicus (Loew, 1869), P. chrysozygos 
(Wiedemann, 1817) and P. comitialis (Kowarz, 1867) (Khaghaninia et al., 2013b); Diaphorus sublautus Negrobov, 2007, Dolichopus austriacus Parent, 1927, D. campestris Meigen, 1824, D. immaculatus Becker, 1909, D. subpennatus d'Assis Fonseca, 1976, D. ungulatus (Linnaeus, 1758) and Hercostomus phoebus Parent, 1927 (Khaghaninia et al., 2014a); Chrysotimus molliculus (Fallén, 1823); Hercostomus apollo (Loew, 1869); Hydrophorus balticus (Meigen, 1824); Medetera meridionalis Negrobov, 1967; Orthoceratium lacustre (Scopoli, 1763) and Poecilobothrus principalis (Loew, 1861) (Kazerani et al., 2014a). A new species Dolichopus malekii Grichanov, Khaghaninia, Gharajedaghi was described from the East Azerbaijan province (Khaghaninia et al., 2014b).

So, joint efforts of Khaghaninia, Gharajedaghi, Alikhani and Grichanov in collecting and treatment of longlegged flies increased the Iranian fauna up to 66 species apart from several unidentified morphospecies.

Farzaneh Kazerani (the University of Tabriz) with the help of Drs. Khaghaninia and Grichanov identified and published a lot of new species records for the country based on material previously collected in 2010-2013 by Dr. S. Khaghaninia in East Azerbaijan, West Azerbaijan and Ardabil provinces, by Drs. A. Nadimi and M. Khayrandish (the Tarbiat Modares University, Tehran) in Mazandran and Guilan provinces. It is worth noting that this material was not checked by Igor Grichanov, but he noted (from photos sent him by Kazerani) many undescribed species of Dolichopodidae. The following 36 species were added to the Iranian fauna resulted from the Kazerani's research (some identifications must be confirmed): Rhaphium antennatum (Carlier, 1835), R. auctum Loew, 1857, R. penicillatum Loew, 1850 and R. lanceolatum Loew, 1850 (Kazerani et al., 2013); Dolichopus siculus Loew, 1859, D. kiritshenkoi Stackelberg, 1927 and D. plumipes (Scopoli, 1763) (Kazerani et al., 2014b); Chrysotus cilipes Meigen, 1824, C. collini Parent, 1923, C. neglectus (Wiedemann, 1817) and Asyndetus latifrons (Loew, 1857) (Kazerani et al., 2014c); Gymnopternus assimilis (Staeger, 1842), G. blankaartensis Pollet, 1991, Hercostomus convergens (Loew, 1857), Medetera flavipes Meigen, 1824, M. micacea Loew, 1857, M. muralis Meigen, 1824, M. seguyi Parent, 1926, M. truncorum Meigen, 1824 and Rhaphium fascipes (Meigen, 1824) (Kazerani et al., 2014d); Campsicnemus curvipes (Fallén, 1823), C. umbripennis Loew, 1856, Sympycnus pulicarius (Fallén, 1823) and Syntormon pumilus (Meigen, 1824) (Kazerani et al., 2014e); Syntormon aulicus (Meigen, 1824), S. denticulatus (Zetterstedt, 1843), S. macula mediterraneus Grichanov, 2013, Teuchophorus monacanthus Loew, 1859, T. spinigerellus (Zetterstedt, 1843) (Kazerani et al., 2014f); Gymnopternus angustifrons (Staeger, 1842), Poecilobotbrus bigoti Mik, 1883, Sybistroma clara (Negrobov, Onishchenko, 1991), S. crinipes Staeger, 1842 (Kazerani, Talebi, 2014); Sciapus basilicus Meuffels, Grootaert, 1990 , S. heteropygus Parent, 1926 and S. medvedevi Negrobov, Selivanova, 2009 (Kazerani et al., 2015). In addition, new species Sciapus talebii Kazerani, Grichanov was described from the Iran (Gulian province) (Kazerani et al., 2015), and Sybistroma occidasiatica Grichanov, Kazerani was described from East Azerbaijan province, Israel and Turkey (Grichanov, Kazerani, 2014).

Recently, Dr. Marc Pollet (the Research Institute for Nature and Forest, Brussels, Belgium) checked the newly collected Iranian material and added the following seven species to the Iranian fauna: Rhaphium brevicorne Curtis, 1835, R. caliginosum (Zetterstedt, 1843), Lamprochromus speciosus (Loew, 1871), Syntormon silvianus Pârvu, 1989 and S. filiger Verrall, 1912 (Kazerani et al., 2016); Argyra vestita (Wiedemann, 1817) and Chrysotus obscuripes Zetterstedt, 1838 (Khaghaninia et al., 2016).

As a result, the number of reported species from this country is now 111 species. Most of the species are widespread across the Palaearctic Region or across Europe; nevertheless, Dolichopus malekii, Sciapus iranicus, S. talebii, Syntormon giordanii and S. iranicus are at present endemics of Iran, and Diaphorus sublautus, Dolichopus siculus, D. kiritshenkoi, Hercostomus libanicola, H. phoebus, Medetera pavlovskii, Poecilobothrus armeniorum, Sciapus medvedevi, Sybistroma clara, S. leptocerca and S. occidasiatica are rare species in Iran and East Mediterraneans. Regarding Syntormon silvianus reported by Kazerani et al. (2016), I consider the species doubtful, being a possible synonym of widely distributed Syntormon monilis (Haliday, 1851) (see Grichanov, 2013). Key characters of the two species must be redescribed and accurately figured in order to define their true relations. I suggest that many more species will be revealed in Iran, if new districts and localities are investigated with the use of mass trapping methods. For example, the most recent survey conducted in the Markazi and Lorestan provinces has revealed 16 dolichopodid species including three species new for the country: Medetera jacula (Fallén, 1823), Rhaphium albifrons Zetterstedt, 1843 and Thrypticus bellus Loew, 1869 (Ahmadi et al., 2016).

\section{CONCLUSION}

The nearest steps in the faunal investigation of predatory long-legged flies in Iran are as follows: continuation of description of Iranian fauna, including description of new species, with special attention to southern and eastern provinces of the country; molecular investigation of sibling species or phenotypes of the same species (e.g., Medetera jacula and M. meridionalis, Syntormon pallipes (phenotypes pallipes and pseudospicatus), Sybistroma occidasiatica (phenotypes A and B), etc. compiling an annotated catalog of Iranian species; studying ecology and biology of abundant species and their role in agricultural and forest ecosystems.

\section{ACKNOWLEDGEMENTS}

This paper was partly supported by the grant of the Russian Foundation for Basic Research N 14-0400264-a to Oleg P. Negrobov.

\section{REFERENCES}

Ahmadi, A., Gheibi, M., Ostovan, H., Hesami, S., Grichanov, I.Ya. (2016). New records of Dolichopodidae (Diptera) from Central Provinces of Iran. Halteres, 7, 191-196. Available from: http://www.antdiversityindia.com 
Becker, Th., Stein, P. (1913). Persische Dipteren von den Expeditionen des Herrn N. Zarudny 1898 und 1901. Ez̧hegodnik Zoologicheskogo Muzeya Imperatorskoi Akadedmii Nauk, 17(3-4), 503-654.

Grichanov, I.Ya. (2007). A checklist and keys to Dolichopodidae (Diptera) of the Caucasus and East Mediterranean. St.Petersburg: VIZR, 1-160 (Plant Protection News Supplements). Available from: http://www.diptera.info/downloads/Grichanov 2007b.pdf (accessed 26 June 2016).

Grichanov, I.Ya. (2013). Systematic notes on West-Palearctic species of the genus Syntormon Loew (Diptera: Dolichopodidae). In: Grichanov, I. Ya., Negrobov, O. P. (Eds). Fauna and taxonomy of Dolichopodidae (Diptera). Collection of papers. St.Petersburg: VIZR (Plant Protection News Supplements), 3-26. Available from: https://archive.org/details/GrichanovNegrobovDolichopodidae2013 (accessed 26 June 2016).

Grichanov, I.Ya. (2014). Alphabetic list of generic and specific names of predatory flies of the epifamily Dolichopodoidae (Diptera). St.Petersburg: VIZR, 1-544. (Plant Protection News Supplements, N14). Available from: https://archive.org/details/Grichanov2014DoliBank (accessed 26 June 2016).

Grichanov, I.Ya., Alikhani, M., Rabieh, M.M. (2010). New data on the distribution of Dolichopodidae (Diptera) in Iran. International Journal of Dipterological Research, 21(3), 195-201.

Grichanov, I.Ya., Kazerani, F. (2014). A new species of Sybistroma Meigen (Diptera: Dolichopodidae) from the Middle East with a key to West-Palaearctic species of the genus. Zootaxa, 3866(4), 572-582. http://dx.doi.org/10.11646/zootaxa.3866.4.7.

Grichanov, I.Ya., Negrobov, O.P. (2014). Palaearctic species of the genus Sciapus Zeller (Diptera: Dolichopodidae). St.Petersburg: VIZR, pp. 1-84 (Plant Protection News Supplements, N13). Available from: https://archive.org/details/GrichanovNegrobov2014Sciapus (accessed 26 June 2016)

Kazerani, F., Khaghaninia, S., Grichanov, I.Ya. (2013). The genus Rhaphium Meigen, 1803 (Diptera: Dolichopodidae) in Iran, with new species records for the country. Studia dipterologica, 20(1), 113-119.

Kazerani, F., Khaghaninia, S., Talebi, A.A., Gharajedaghi, Y., Grichanov, I.Ya. (2014a). New Records of Long-Legged Flies (Diptera: Dolichopodidae) from Iran. Acta entomologica serbica, 19(1/2), 25-32.

Kazerani, F., Khaghaninia, S., Grichanov, I.Ya. (2014b). The genus Dolichopus Latreille diversity in three different habitats of East Azerbaijan province, with new records for Iran. Arxius de Miscellània Zoològica, 2013, 11, 134-152.

Kazerani, F., Khaghaninia, S., Grichanov, I.Ya. (2014c). The subfamily Diaphorinae Schiner, 1864 (Diptera: Dolichopodidae) in East Azerbaijan Province with four new species records for Iran. Efflatounia (Efflatoun's Journal of Entomology), 14, 1-8.

Kazerani, F., Khaghaninia, S., Talebi, A.A., Grichanov, I.Ya. (2014d). Faunistic survey of Dolichopodidae in forests of northern Iran with nine species as new records for the country. Zoology and Ecology, 24(3), 266-273.

Kazerani, F., Khaghaninia, S., Grichanov, I.Ya. (2014e). New faunistic records of the subfamily Sympycninae (Diptera, Dolichopodidae) from Iran. Polish journal of entomology, 83(1), 61-69. http://dx.doi.org/10.2478/pjen-2014-0004.

Kazerani, F., Khaghaninia, S., Talebi, A.A., Grichanov, I.Ya. (2014f). New data on the subfamily Sympycninae Aldrich, 1905 (Diptera, Dolichopodidae) from Iran. Dipterists Digest, 21(2), 143-149.

Kazerani, F., Khaghaninia, S., Talebi, A.A., Grichanov, I.Ya. 2015. Genus Sciapus (Diptera: Dolichopodidae) in Iran, with description of one new species and new records. Acta Entomologica Musei Nationalis Pragae, 55(1), 401-409.

Kazerani, F., Khaghaninia, S., Talebi, A.A., Pollet, M. (2016). Faunistic study of Rhaphinae Bigot, 1852 and Sympycninae Aldrich, 1905 (Dip., Dolichopodidae) in North and Northwest Iran, with record of 5 new species for the fauna of Iran. In: 22nd Iranian Plant Protection Conference. Abstract 2023-IPPC22 (in Iranian). Available from: https://ippc22.ut.ac.ir/paper?manu=24502 (accessed 26 June 2016).

Kazerani, F., Talebi, A.A. (2014). Faunistic survey of the subfamily Dolichopodinae (Diptera: Dolichopodidae) in the central and west parts of the Arasbaran forests with 4 species as new records for the fauna of Iran. Iranian Journal of Forest and Range Protection Research, 12(1), 20-29 (in Iranian).

Khaghaninia, S., Gharajedaghi, Y., Grichanov, I.Ya. (2013a). Additional notes about long-legged flies (Diptera: Dolichopodidae) in East Azerbaijan province of Iran. Biharean Biologist, 7(1), 42-47.

Khaghaninia, S., Gharajedaghi, Y., Grichanov, I.Ya. (2013b). Study of the genera Hercostomus Loew, 1857 and Poecilobothrus Mik, 1878 (Diptera: Dolichopodidae) in Kandovan Valley with new records for Iran. Biharean Biologist, 7(2), 73-79.

Khaghaninia, S., Gharajedaghi, Y., Grichanov, I.Ya. (2014a). A contribution to the knowledge of the family Dolichopodidae (Diptera) in East Azerbaijan province of Iran. Check List: The Journal of Biodiversity Data, 10(3), 588-593. http://dx.doi.org/10.15560/10.3.588.

Khaghaninia, S., Gharajedaghi, Y., Grichanov, I.Ya. (2014b). The Dolichopus plumipes species group in the Palaearctic Region with the description of a new species from Iran (Diptera: Dolichopodidae). Journal of Insect Biodiversity, 2(1), 1-9.

Khaghaninia, S., Kazerani, F., Talebi, A.A., Pollet, M. (2016). New records of Diaphorinae (Dip., Dolichopodidae) in Northwest Iran. In: 22nd Iranian Plant Protection Conference. Abstract 2129-IPPC22 (in Iranian). Available from: https://ippc22.ut.ac.ir/paper?manu=24502 (accessed 26 June 2016).

Maslova, O.O. (2006). Revision of the genus Chrysotus (Dolichopodidae, Diptera) of Russia and adjacent territories. Abstract of PhD Thesis. Voronezh: Voronezh LTA, 1-20 (in Russian).

Negrobov, O.P. (1991). Dolichopodidae. In: Soos, A., Papp, L., Oosterbroeck, P. (Eds.). Catalogue of Palaearctic Diptera 7 : Dolichopodidae-Platypezidae. Budapest: Akadémiai Kiadó, 1-291.

Negrobov, O.P., Matile, L. (1974). Contribution à la faune de l'Iran: Diptera, Dolichopodidae. Annales de la Société Entomologique de France, 10, 841-845.

Negrobov, O.P., Stackelberg, A.A. (1971-1977). Dolichopodidae, Unterfamilie Medeterinae. In: Lindner, P.E. (Ed.). Die Fliegen der Palaearktischen Region. Stuttgart, IV, 29, 284 (1971), 289 (1972), 302, 303 (1974), 316 (1977), $238-354$.

Stackelberg, A.A. (1941). Dolichopodidae, Unterfamilie Dolichopodinae. In: Lindner, P.E. (Ed.). Die Fliegen der Palaearktischen Region. Stuttgart, IV, 5(29), 138, 177-224. 